\title{
TEMAS EM DEBATE
}

UFRGS, Porto Alegre, n.2, p.205-26, 1995.

WINNICOTT, D.W. A Criança e o seu mundo. Rio de Janeiro: Zahar, 1966.

\section{EDUCAÇÃO BRASILEIRA: DA REALIDADE À FANTASIA}

\author{
WALTERE. GARCIA \\ Presidente da Associação Brasileira de Tecnologia Educacional - ABT \\ Diretor do Instituto Paulo Freire
}

\section{RESUMO}

O texto que aqui se apresenta por solicitação do Grupo de Política Educacional da ANPED no ano de 1988 talvez não acrescente nada de novo ao que todos já sabem a respeito do andamento da gestão educativa em nosso país. Na maior parte da análise retomarei conceitos e informações que já são de domínio público, com exceção de algumas nuances que surgem na condução política das questóes educativas ao longo dos últimos anos, com o aparecimento do marketing como meio fundamental de produzir fatos e criar uma meta-realidade, bastante distinta do que ocorre no cotidiano da vida escolar do país, com repercussões inevitáveis sobre o rumo dos acontecimentos.

POLITICASEDUCACIONAIS-ANPED-GESTÃOEDUCACIONAL-BRASIL

\section{ABSTRACT}

BRAZILIANEDUCATION: FROMREALITY TO FANTASY. The text presented here: at the request of the Educational Policy Group of the ANPED, perhaps adds nothing new to what everyone already knows about the state of education in our country. With the exception of some nuances that have arisen in the political management of educational issues during recent years, the better part of the analysis restates concepts 
and information already existing in the public domain. However, the emergence of marketing as a fundamental means of producing facts and creating a meta-reality very different from what is really happening in the country's day-to-day school life has inevitable repercussions on the course of events.

Em levantamento efetuado na década de 80 (Garcia, 1991), constatei que até o ano de 1985 o país já havia tido - desde a criação do Ministério da Educação e da Saúde, no começo dos anos trinta - a média de um ministro (interino ou efetivo) por ano de existência do Ministério da Educação e Cultura - MEC. Fazendo exercício de memória, constato que essa proporção se mantém até os dias de hoje.

Com a ininterrupta sucessão de ocupantes do posto de ministro, numa área em que todos consideram fundamental o desenvolvimento de programas de médio e longo prazos que demandam, sobretudo, continuidade, é possível identificar algumas características que se repetem com irritante constância, como, por exemplo, o abandono de propostas que vinham sendo executadas, a mudança de prioridades enunciadas e uma intensa preocupação com a divulgação de dados e informações sobre a gestão do ocupante do cargo, como que a querer compensar a expectativa da curta permanência na função, diante da dificuldade de deixar marcas mais profundas durante o exercício do mandato de ministro.

Com raras exceções, e felizmente elas existem, isso se dá como um ritual que se repete à exaustão, e os que já viram esse filme, especialmente depois da construção de Brasília como cidade administrativa, já se habituaram com os jogos da sucessão e da vacuidade do poder educacional.

A alta rotatividade no comando da política educativa nacional trouxe como conseqüência a pouca valorização do posto maior da gestão educativa, principalmente nas últimas décadas. No vaivém das composições políticas, a Educação acabou sendo relegada à condição de moeda de compensação para alguém esquecido ou que aderiu de última hora ao grupo hegemônico. Exemplos desses arranjos não faltam na crônica brasiliense e, talvez, se possa entender o posto de ministro como de expectativa para "coisa melhor", quando ocorrer a próxima reforma ministerial. As exceções apenas confirmam o quadro geral em que se move a cena educacional. Perante o jogo do poder, inclusive, o MEC é visto como um ministério frágil.

A análise de Ronald Braga ( 1984 ) indica, por exemplo, que a gestão Ludwig ganhou alguma força de barganha junto à área econômica por ser ele um representante do estamento militar, fato que não vinha ocorrendo com outros ministros-educadores ou originários da chamada sociedade civil. Mais recentemente, assistimos à emergência de ministros "fortes", sobretudo graças à importância atribuída à educação após a Conferência Mundial da Tailândia e também em razão das vinculações pessoais desses titulares com o presidente da República. É o caso do ex-ministro Murílio Hingel e do atual ministro Paulo Renato Souza.

Essa rotina de alterações constantes, via de regra, se reproduz nas unidades federadas que tendem a seguir o modelo de gestão política adotado em nível central. Muitos estados, principalmente os mais dependentes dos recursos repassados pelo governo federal, repetem em sua estrutura o organograma adotado pelo MEC, criando linhas de comunicação direta 
entre os profissionais que gerenciam os programas ocasionalmente adotados. Mudando as prioridades no centro, estas se refletem diretamente nos estados, com as conseqüências que todos conhecemos.

\section{O ESTILO DA POLÍTICA EDUCACIONAL}

A continuidade da política educacional, com as interrupções periódicas conhecidas, caracteriza-se como um fenômeno que venho chamando de continuidade descontínua. Embora a expressão seja paradoxal, ela se justifica na medida em que o processo de gestão não se dá por cumulatividade, mas por interrupções. Ou seja, as ações, a cada período de tempo, mudam de rumo. Propostas - não se sabe se boas ou más, até porque muitas delas dificilmente poderiam ser devidamente avaliadas tal a intempestividade de seu aparecimento e esquecimento - são substituídas por outras, provocando desmobilização de esforços, substituição de equipes, sem contar a descrença que tais mutações provocam nos profissionais encarregados da operacionalização das metas.

Nesse panorama de descontinuidade, encontramos por vezes uma política educacional efetivamente próspera e que se mantém por muito tempo. Ela ocorre em áreas determinadas e em situações especiais como, por exemplo, a atuação do Instituto Nacional de Estudos Pedagógicos - INEP - sob a gestão de Anísio Teixeira ou a política de formação de quadros de alto nível, graças à existência de órgãos como o Conselho Nacional de Pesquisa - CNPq (que sempre teve apoios políticos fortes além da área educacional) e a Coordenadoria de Aperfeiçoamento de Pessoal de Nível Superior - CAPES (também uma iniciativa de Anísio Teixeira).

O comum, entretanto, é a existência de programas e projetos para atendimento a demandas específicas e que se tornam mais facilmente operacionalizáveis, quer seja por realocação de recursos consignados ou criando linhas especiais de repasses aos estados e municípios. Em alguns estudos, pode-se observar que não se economizam programas e projetos educacionais.

Em pesquisa efetuada pela Fundação Carlos Chagas, foi constatado que, no período de 1975 a 1986, o Ministério da Educação deu início a 35 projetos e programas nas áreas então consideradas prioritárias que eram o ensino de primeiro grau, o ensino de segundo grau e o ensino supletivo. O relatório aponta as dificuldades e descontinuidades da implantação das propostas, mesmo elas estando sob o abrigo do II e III Planos Setoriais para a Educação e Cultura, no período analisado (Gatti, Sawaia, 1987).

Apesar de tudo isso, no entanto, a educação sempre esteve na agenda dos grupos mais representativos da sociedade brasileira. Essa importância possibilita que alguns temas permaneçam na pauta dos administradores da educação, até porque pode significar um toque de modernidade no trato das questões educacionais. Isso acontece, por exemplo, com as avaliações do sistema educacional, propostas que se vêm mantendo com mais freqüência, 
desde a gestão Bornhausen em 1986.

Os processos constituintes das últimas décadas, as lutas pela Lei de Diretrizes e Bases LDB, ao lado de outras relativas à defesa dos direitos da infância, provocaram ascendentes movimentos de reivindicação por mais e melhor educação. Isso explica também a importância dos temas da descentralização, da autonomia da escola, da gestão democrática, entre outros.

Conforme Vieira (1998), os temas que permanecem são fruto de "escolhas e recortes" em razão de contingências e circunstâncias que necessitariam de uma análise mais aprofundada.

A importância da educação, no entanto, faz com que políticos, sequiosos por agradar seus eleitores, reconheçam essa nova realidade, propondo maior envolvimento do poder público com a questão educacional. A contrapartida é que, nos dias de hoje, as promessas são cobradas com maior insistência pela população. Associações de toda natureza reforçam a prioridade educacional da sociedade e a Conferência Mundial de Educação para Todos colocou na ordem do dia deste final de século a educação como política pública relevante. De outra parte, o direito à educação entra na agenda dos grupos organizados da sociedade e muitos reivindicaram nos tribunais a disponibilidade de vagas nas escolas públicas (Oliveira, 1998).

Ainda, como conseqüência da maior participação da cidadania nos assuntos educacionais, observa-se também que, por anos seguidos, o ensino público, entre nós e em vários países, experimentou taxas extraordinárias de crescimento, sobretudo no ensino fundamental. A universalização do atendimento, meta proposta por inúmeros encontros internacionais e reiterada pela Conferência de Jomtien, passou a ser a palavra de ordem do país, apesar dos baixos níveis de desempenho do sistema, especialmente em razão das altas taxas de evasão e repetência.

No caso brasileiro, em especial, a legislação estipulou recursos vinculados na Constituição e em lei ordinária, visando à garantia de um mínimo de investimentos no setor. Com a Constituição de 1988, inclusive, assegurou-se o comprometimento de recursos (artigo 60 das disposições constitucionais transitórias) para eliminação do analfabetismo e melhoria do ensino ao longo de dez anos.

A ampliação das demandas educacionais, aspiração amadurecida da sociedade brasileira, em processo de redemocratização durante os anos oitenta e noventa, encontra grandes obstáculos com o agravamento da crise do modelo de desenvolvimento adotado pelo país, a partir dos anos sessenta, com a internacionalização da economia, a crescente dependência de capitais externos, o extraordinário crescimento das dívidas interna e externa, configurando um quadro que exigia soluções capazes de enfrentar um processo de ruptura com os padrões propostos pelas grandes potências (alternativa de riscos incalculáveis) ou aceitar programas que levassem avante a abertura econômica e de alinhamento com as diretrizes dos organismos financeiros internacionais. Prevaleceu a segunda orientação, com a ascensão de Collor ao poder, que se consolida com Fernando Henrique Cardoso. Entre os dois, o governo Itamar, como interregno que tentou adiar o desfecho que viria a se tornar inevitável. Nessa perspectiva, a análise da questão educacional como política pública torna-se relevante, 
como será examinada mais adiante.

Para um debate mais aprofundado do tema proposto, os anos noventa são emblemáticos de uma nova realidade anunciada em diferentes momentos e situações. $\bigcirc$ agravamento das contradições, espelhadas na Constituição Federal, inspirada num modelo de Estado de Bem-Estar Social, diante de uma visão economicista das políticas sociais, acaba por se acentuar, provocando rupturas, com definição clara no atual governo. Modificam-se posturas de condução das ações governamentais, a tecnocracia muda de perfil com a conseqüente desqualificação dos quadros permanentes da burocracia estatal. Esse é o panorama geral no qual se move a política educativa nos anos noventa e em que os educadores passam a ocupar seu espaço, de maneira distinta da que vinha ocorrendo em outros tempos.

\section{A EDUCAÇÃO COMO POLÍTICA PÚBLICA}

Ao falar de políticas públicas importa considerar, como o faz apropriadamente Janete Azevedo (1997), os recursos de poder que contribuem para sua definição, o papel do Estado e da máquina governamental e a ação da sociedade - sua memória, valores, representações, símbolos etc. que impulsionam ou relegam a segundo plano determinadas propostas. No caso da educação, inclusive, essa se encontra condicionada por outros fatores da sociedade como, por exemplo, os de natureza política, de natureza econômica e até ideológica. A maior ou menor participação dos grupos organizados da sociedade é o que vai determinar maior ou menor prioridade à política educacional. Isso é especialmente importante de ser analisado com o agravamento da crise do modelo de desenvolvimento como a que se abate mais agudamente sobre o país nos anos oitenta e noventa.

As ambigüidades do processo político brasileiro, ao contrário do que se poderia esperar, tornaram-se mais chocantes com a Constituição de 1988. Incorporando em seus dispositivos conquistas das sociedades avançadas com respeito a questões de educação, meio ambiente, infância, trabalho, entre outras, o texto constitucional define um rumo que se esperava viesse redirecionar as políticas - especialmente as sociais - no sentido de resgatar os direitos de cidadania, promover a eqüidade, enfim, ajudar a construir um país menos desigual e mais democrático.

As iniciativas relativas ao Plano Decenal de Educação, os diferentes pactos - de educação, da infância, criaram uma perspectiva animadora quanto às possibilidades de efetivamente a política educativa vir a ocupar o seu lugar prioritário nas ações do Estado. Esta mobilização de diferentes direções da sociedade, no entanto, freqüentemente esbarra em resistências de grupos organizados - sobretudo nas áreas políticas e econômicas comprometidas e articuladas com os interesses da nova ordem internacional. A sensação que se tem desse embate, que não define com clareza para que lado o país quer seguir em matéria educacional, é indicativa de uma sociedade fortemente marcada pelo processo de evolução histórica, na qual a cultura do privilégio e da exclusão são mais fortes do que as propostas de 
igualdade e de cidadania para todos.

No dizer de Sofia L. Vieira (1998), o país encontra-se em fase de transição e ainda não foi capaz de definir um novo projeto hegemônico para o setor educacional. Segundo a autora, ainda, a incapacidade ou ausência de vontade política para resolver problemas educacionais estimulam visões antagônicas e dicotômicas, configurando uma "metodologia dos contrários", expressão utilizada por Antônio Cândido que Sofia adota para configurar as contradições que impedem uma definição mais transparente de política educacional.

Em outra linha de reflexão, Saviani (1998) indica, a respeito do Plano Nacional de Educação - atualmente em exame no Congresso -, que ele, como toda a educação, está mais voltado para a "racionalidade financeira" para ajustar-se mais facilmente aos desígnios da nova ordem globalizada.

A nova configuração, entretanto, não veio do nada. Ela foi sendo construída num processo lento e persistente e foi testada em outros países do continente, até sua plena vigência entre nós. A literatura educacional, a partir dos anos setenta, em países como Chile, Argentina e México, entre outros, revela como as novas propostas vão-se insinuando para ganhar ares de verdades inquestionáveis. As necessidades de avaliação do sistema educacional, de reduzir os investimentos públicos no ensino superior, de buscar parcerias com setores produtivos são, ao lado de muitas outras, propostas que vão sendo sugeridas aos governantes como solução de todos os problemas educativos. Junto com essas novas temáticas, as ofertas de empréstimos internacionais para a educação tornam-se mais disponíveis, desde que sigam os figurinos que as acompanham.

No Brasil, por exemplo, esses recursos começam a surgir mais amiúde nos anos oitenta. Hoje, década de noventa, a Agência Brasileira de Cooperação, do Ministério das Relações Exteriores, está examinando cerca de uma dezena de projetos em várias modalidades de cooperação, sem contar que mais de quinze estão em execução, com apoio de agências de financiamento ou de cooperação propriamente dita e que envolvem não apenas o governo federal, mas também estados e municípios.

A internacionalização (Vieira, 1998. p.55 e ss) da política educacional permite ao país adotar a "globalização da agenda educativa", em que temas, como o da avaliação escolar, constituem projetos multinacionais de investigação. A questão dos "parâmetros curriculares" hoje é debatida em vários países. Por outro lado, a introdução de megaprojetos, como o do Nordeste, financiado com recursos do Banco Mundial e do governo brasileiro, torna mais fácil a difusão da ideologia da racionalidade econômica. Junto com ela surgem as discussões do seguinte tipo:

- o país não necessita de mais recursos para a Educação, precisa é gastar melhor;

- já temos vagas para todos, precisamos é melhorar o desempenho;

- o problema do ensino não é a evasão, e sim a repetência; 
- o ensino superior gratuito para os alunos é um luxo inaceitável para um país subdesenvolvido.

O ruim destas afirmações é que elas representam, quando muito, meias-verdades e ajudam a confundir políticos despreparados e a população, em geral, que tendem a acreditar nas mensagens emitidas pela mídia com grande destaque. Essa participação dos financiamentos internacionais para a educação, por outro lado, deve ser incrementada de maneira substancial ao longo dos próximos anos.

Falando na reunião de ministros da educação da região, em encontro efetuado em Brasília, Nancy Birdsall (1998), vice-presidente do Banco Interamericano do Desenvolvimento - BID -, indicou que nos próximos cinco anos os investimentos do BID chegariam aos cinco bilhões de dólares no continente. Nessa mesma oportunidade, Birdsall indica que enquanto os anos setenta foram dominados por investimentos em infra-estrutura, a década de oitenta privilegiou o material pedagógico. Nos anos noventa, será estimulada a permanência na escola e o desenvolvimento educacional. E conclui: "Podemos investir em programas de tecnologia, educação à distância e intercâmbios".

Como mencionado anteriormente, os antagonismos flagrantes entre os avançados dispositivos da "Constituição Cidadã" e as orientações do processo de internacionalização e da globalização econômica levam muitos a questionar os dispositivos da Carta Magna de 1988. Em seminário realizado no Rio de Janeiro, em 1991, representantes do Banco Mundial e alguns especialistas brasileiros discutiram alternativas de como investir mais no ensino básico e de como reduzir os elevados investimentos no ensino superior gratuito. Richard Sabot, do Banco, mencionou que "tempos de crise como este no Brasil, são ideais para se tomar decisões difíceis, mas necessárias, como a de acabar com o ensino superior gratuito, porque a falta de alternativa reforça a urgência" (Silva, 199I). No mesmo evento, Eric Hanushek, do MIT, defendeu a tese de que cada dólar investido em regiões do país, em livros, por exemplo, significa um ganho de quatro dólares que deixarão de ser gastos com repetentes.

\section{OS ANOS NOVENTA}

Em sua análise sobre a transição educacional do país, Vieira (1998), examinando o período de 85 a 95, revela que se o governo Sarney pode ser caracterizado como de indefinições, o de Collor mostrou ser de muito discurso e pouca ação. Itamar identificou-se por tentar retomar os princípios da Constituição de 1988 e os temas ligados à educação como componente da cidadania. Fernando Henrique Cardoso surge como o governante que executa as reformas, com definição de metodologias de ação, recursos e consolidando um novo perfil educativo.

Essas arritmias, ao longo dos primeiros anos da década de noventa, revelaram as 
ambigüidades e incertezas dos processos de mudança educacional à luz dos novos dispositivos constitucionais. $\bigcirc$ governo Collor, (que teve em Carlos Chiarelli o seu primeiro-ministro da educação), apesar de ter-se comprometido com os principais documentos nacionais e internacionais de políticas de apoio à infância e à educação, foi extremamente reticente quanto a levar avante um compromisso mais efetivo com o conteúdo das propostas que endossou. Fernando Collor de Mello, em artigo publicado em 92 na Folha de S. Paulo, dá indicação dos rumos que defende, do que ele chama "ideário social-liberal": a defesa da educação como instrumento da cidadania e a defesa da ciência e tecnologia como meio de viabilizar as "reais necessidades humanas".

Nesse quadro, Collor identifica três direções importantes que deveriam ser reforçadas: a) mobilização da sociedade para a melhoria da formação básica; b) apoio à universidade para que ela forme não apenas técnicos com visão estreita, mas pessoas "detentoras de saber universal e eclético"; c) engajamento dos setores produtivos da sociedade, como forma de possibilitar ampliação das atividades de pesquisa e desenvolvimento, por meio de uma articulação entre universidades, empresas e instituições científicas.

Em sua ação político-educacional, Collor criou alguns projetos nacionais (como os centros integrados de apoio à criança com forte ênfase na construção de edifícios), e além disso pouco avançou.

O ministro Chiarelli, apesar de se definir como professor, pouco confiava nas propostas dos educadores. Sua gestão foi marcada por conflitos permanentes com a Comissão Nacional de Alfabetização e Cidadania, criada para implementar as recomendações da Conferência de Jomtien. Numa das reuniões mais difíceis da comissão, com a presença do ministro, este afirmou textualmente que ela existia para auxiliá-lo e que, portanto, ele decidia o que deveria ou não ser feito. A mobilização feita pela comissão, junto a estados e municípios, praticamente não foi levada em conta por Chiarelli.

Em avaliação das ações do Programa Nacional de Alfabetização e Cidadania - PNAC - efetuadas pelas comissões estaduais, Maria Beatriz M. Lüce, Osmar Fávero e Sérgio Haddad (1992) concluem:

....lastimavelmente, o próprio programa corre o grave risco de se constituir apenas num episódio. Não se tem o direito, no entanto, de promover uma ampla mobilização e deixar sem resposta as solicitações dela advindas, ou sem justificativa as opções de financiamento feitas através de outros mecanismos e critérios.

As lições desse fracasso viriam a ser retomadas, mais tarde, na gestão Hingel, com o Plano Decenal de Educação.

Em realidade, o governo Collor pouco se mostrou em matéria de disposição para mudar a realidade educacional, apesar do apoio político que revelou ao firmar os compromissos de Jomtien e da Cúpula de Presidentes pela Infância, em Nova York. Nesse sentido, o caráter promocional de Collor funcionou bem ao colocar-se ao lado das "boas causas"e foi 
muito mais eficiente do que sua capacidade de implementar as propostas que adotou. Logicamente ele tinha uma percepção muito clara do efeito de marketing junto à população.

A gestão do ministro Goldemberg, já no final deste período, pouco contribuiu para algum avanço importante. Em artigo publicado na ocasião, Goldemberg ( 1992 ), praticamente, faz um balanço de sua gestão, indicando que o ensino básico deveria ser responsabilidade maior dos estados e municípios e, condenando o caráter corporativo, repete inúmeras críticas ao comportamento das universidades - especialmente as federais. Dizia-se pelos corredores do Ministério da Educação e Cultura - MEC - que o ministro tinha muito pouca simpatia pelo ensino fundamental. No artigo mencionado, ele indica que o "analfabetismo dos adultos é uma doença em extinção no Brasil...." Esta visão conduziu o MEC a deixar de lado a educação de jovens e adultos analfabetos em sua curta gestão.

Com o processo de impeachement, que se instaurou no Congresso e culminou com o afastamento de Collor, assumiu a Presidência da República Itamar Franco. Para a pasta da Educação chama Hingel, um mestre-escola com participação em várias atividades ligadas ao setor educacional, seja como consultor do MEC em períodos anteriores, seja como professor universitário em Juiz de Fora. Foi, ainda, Secretário Municipal de Educação naquela cidade e também diretor da Faculdade de Educação da Universidade Federal de Juiz de Fora - UFJF.

Embora pouco conhecido do grande público, Hingel revelou-se, desde o início, como alguém que pisava em terreno que lhe era bastante familiar. Seu diálogo com os grupos da área educacional foi fácil e os entendimentos caminharam mais rapidamente do que se poderia esperar para alguém recém-chegado a uma estrutura tão complexa e absorvente. Em seu Compromisso de Posse, Hingel dá uma demonstração do que viria a ser a sua gestão, ao indicar os vários tipos de colaboração que esperava de estados, municípios, empresários, professores, servidores do MEC, entre outros, revelando uma percepção bastante objetiva das soluções que o país vinha reclamando e que se materializariam na prioridade concedida à questão educacional.

Para Hingel, seu compromisso abrangia oito pontos:

I - A educação é a verdadeira prioridade nacional. 2- Todos os brasileiros, independentemente de qualquer situação, têm direito a uma educação de qualidade. 3-A política educacional deve resultar de uma elaboração participativa capaz de dar unidade às ações educativas dos diversos organismos do governo no âmbito nacional. 4- É indispensável o desenvolvimento da capacidade crítica pelo processo educativo diante da comunicação social, entendido como uma responsabilidade da família, da escola e da comunidade. 5- Há de ser assegurada, progressivamente, a gratuidade total para o aluno do ensino fundamental ( $\mathrm{I}^{\circ} \mathrm{grau}$ ), desde que resolvidos em um primeiro momento os problemas do ensino de responsabilidade do Poder Público. Essa gratuidade está assegurada também em níveis de $2^{\circ}$ grau e no ensino superior nas unidades escolares de responsabilidade do Poder Público federal. 6- O educador será devidamente valorizado como pessoa, como cidadão e como profissional. 7- A educação terá que vivenciar com serenidade adulta, tranqüilidade e segurança os conflitos e tensões sociais que nos envolvem. 8- As universidades e instituições de ensino em geral serão convocadas a se colocar a serviço do desenvolvimento do ser humano e da sociedade, da transformação das estruturas econômicas, jurídicas e sociopolíticas injustas, da procura de uma soci- 
edade mais participativa e solidária e de uma cultura encarnada na vida do povo. (1992)

A partir deste discurso, Hingel começa efetiva mobilização junto a diferentes instâncias, buscando retomar o debate educacional no país. Estados e municípios, bem como outros setores representativos da sociedade civil, são estimulados a tomar posição sobre as questões educacionais e a materialização de toda essa movimentação culmina com a Semana Nacional de Educação para Todos - realizada no período de 10 a 14 de maio de 1993. O ponto alto do evento se traduziu no Compromisso Nacional de Educação para Todos, firmado por lideranças representativas da União, dos Estados e municípios.

Entre os pontos importantes do compromisso, vale a pena mencionar o destaque dado à necessidade de garantir a institucionalização e a continuidade das políticas voltadas para a educação, com a garantia de recursos que possibilitassem a melhoria da qualidade e a elevação dos padrões de escolaridade média à população. Outros pontos importantes que constam do documento são os relativos à valorização social da profissão do professor e o referente ao regime de colaboração entre União, Estados e municípios e outros setores organizados da sociedade. Finalmente, foi recomendada a criação de um organismo permanente de mobilização em prol da educação fundamental, que seria assessorado por um grupo técnico de acompanhamento do Plano Decenal que começa a ser distribuído em sua versão preliminar para debate em todo o país, a partir de junho de 1993.

Com essa mobilização o Brasil inicia atuação mais decisiva no Grupo EFA-9 (grupo de nove países com maiores índices de analfabetismo) e passa a receber apoio mais efetivo da UNESCO e de outros organismos para reunir-se, periodicamente, intercambiar experiências e seguir debatendo estratégias para melhorar seu desempenho educativo dentro do marco do Plano Decenal de Educação. A estratégia básica de construção do plano, segundo Célio da Cunha, seu principal articulador, foi a de " respeitar a organização federativa do país e as diferenças regionais existentes, permitindo a cada unidade federada e a cada município, com base nas diretrizes e metas globais do plano, definir o seu compromisso e estabelecer as suas metas" (1994).

A mobilização produzida teve seu ponto alto na Conferência Nacional de Educação para Todos, realizada em Brasília, no período de 29 de agosto a 2 de setembro de 1994, com a presença de 1.600 participantes credenciados de todo o país, representando distintos segmentos do poder público e da sociedade civil. $\bigcirc$ evento significou a culminância de um processo que passou por debates nas escolas, realização de simpósios e seminários temáticos e que se consolidou em inúmeros relatórios e documentos de trabalho para apresentação na conferência.

O momento marcante da Conferência Nacional de Educação para Todos foi a aprovação do Acordo Nacional de Educação para Todos, proposta que foi trabalhada no âmbito do Grupo Executivo, do Comitê Consultivo e do Fórum Permanente do Magistério, grupos que assessoravam o ministro no Plano Decenal. Desses debates participaram, entre outros, organismos como o Conselho Nacional de Secretários de Educação - CONSED -, União 
Nacional de Dirigentes Municipais de Educação - UNDIME -, Conselho de Reitores das Universidades Brasileiras - CRUB, Fórum dos Conselhos de Educação, Confederação Nacional dos Trabalhadores em Educação - CNTE. As principais conclusões do acordo indicam os compromissos de cada ator público com respeito ao ensino fundamental, o piso salarial profissional para o professor (que viria a ser consolidado em documento firmado ao final do ano de 1994). Ao respaldar todas as propostas, a indicação do "acordo configura-se como um pacto pela qualidade" na expressão de Hingel (Brasil, 1994).

A Constituição de 1988 foi o principal referencial em que se apoiaram os elaboradores do Plano Decenal e do Acordo dele decorrente. Tanto é verdade que nos compromissos previstos, no item I, mencionam-se, explicitamente, a imperiosa necessidade de manutenção do artigo 212 e o cumprimento dos percentuais mínimos de financiamento educacional. Da mesma forma, reitera-se a importância do artigo 60 das Disposições Constitucionais Transitórias (que mais tarde viria a ser suprimido). Os signatários do Acordo propuseram, ainda, ações emergenciais, em que a mais importante se referia ao piso salarial nacional dos professores, tema que vinha sendo debatido pelo fórum e que gerou documento-compromisso firmado ao final do governo.

O calendário, última parte do Acordo, que deveria avançar pelo novo governo, previa ainda a institucionalização de colegiados - nas três instâncias de governo - para acompanhamento da implementação do plano, a fixação de padrões e conteúdos mínimos de ensino, a implementação do piso salarial profissional do magistério e a fixação de modelos de distribuição dos encargos educacionais entre União, Estados e municípios.

Uma das últimas providências adotadas com respeito ao Plano Decenal, na gestão Hingel, foi a reunião do Conselho do Plano, em 18 de novembro de 1994. Nessa oportunidade, o colegiado considerou que o êxito atingido com a mobilização dos anos 1993 e 1994 deveria ser mantido, sobretudo junto a estados e municípios e outros grupos da sociedade civil. Foi recomendada, ainda, a realização de encontro com o grupo de transição do governo recém-eleito com o referido conselho, evento que nunca se materializou.

$O$ destaque dado neste informe ao Plano Decenal deve-se ao fato de que, efetivamente, ele marcou de maneira definitiva a gestão de Murílio Hingel à frente do MEC. No entanto, outras ações também foram desenvolvidas, como o início do novo Projeto Nordeste de Apoio à Educação Básica (após anos de negociação com o Banco Mundial); a descentralização das ações da Fundação de Apoio aos Estudantes - FAE - nas áreas de merenda e livro didático; a realização de avaliação dos livros didáticos; o início do Programa de Avaliação das Universidades e a reformulação dos Centros Integrados de Apoio à Criança - Ciacs, que passam a se chamar Centros de Apoio Integral à Criança - CAICs e foram abrigados sob a orientação do Programa Nacional de Apoio à Infância e Adolescência - Pronaica. A desativação do Conselho Federal de Educação foi também uma decisão bastante marcante desse período. 


\section{O GOVERNO FERNANDO HENRIQUE CARDOSO}

O governo Fernando Henrique Cardoso assume o país com amplo apoio popular, advindo da estabilidade da moeda. A equipe econômica praticamente se mantém com a mesma orientação inicial do Plano Real, com forte restrição do crédito e elevadas taxas de juros. No início de 95, no setor educacional, o governo inicia um novo ciclo. Na expressão do próprio chefe de governo, a Educação "é considerada elemento essencial para a conquista de uma sociedade mais justa, solidária e integrada, requisito para o pleno exercício da cidadania e condição para o desenvolvimento econômico". O mesmo documento revela também que somente pela Educação o país terá condição de passar ao grupo dos países desenvolvidos, podendo participar ativa e soberanamente da globalização e da integração dos mercados. A ênfase na qualidade aparece associada a questões de melhor desempenho no trabalho.

O texto destaca que o Plano Decenal de Itamar já havia identificado os pontos cruciais a serem enfrentados, mencionando que os problemas já estavam suficientemente diagnosticados. Apontando na direção da descentralização das ações do MEC, Fernando Henrique indica cinco pontos do Programa Acorda Brasil, para melhoria do ensino fundamental: I) definir um padrão curricular mínimo para o Brasil; 2) descentralizar a compra e a distribuição e promover a melhoria da qualidade do livro didático; 3) repassar diretamente às escolas o dinheiro do Fundo Nacional de Desenvolvimento da Educação - FNDE por meio de convênios com estados e municípios: 4) promover o treinamento de professores mediante o ensino a distância, com a parceria de empresas e da comunidade na aquisição dos equipamentos; e 5) avaliar os alunos de todas as séries, anualmente, nas escolas públicas.

Com esses cinco pontos FHC sinaliza que o ensino fundamental deveria implementar o Plano Decenal, revelando, ainda, outras necessidades, como a reformulação do segundo grau, com o conseqüente envolvimento da experiência do setor privado e busca da excelência na qualificação profissional.

A estratégia adotada pelo governo FHC é de dar grande destaque ao marketing como meio de difundir as suas realizações no campo educacional. Em suas primeiras ações de grande visibilidade, o presidente vai à televisão falar de educação e, segundo a revista Veja (1995), "FHC cometeu a descortesia de não avisar que, em vez de apresentar propostas originais, estava prestando uma homenagem a seus antecessores". A revista menciona, ainda, que muitas das ações já haviam sido iniciadas por Hingel e outras por Chiarelli e Goldemberg. Em seguida, a mesma publicação cita as aulas que o presidente ministrou em Santa Maria da Vitória, na Bahia, numa escola primária e o encontro realizado com professores na cidade de Diamantina, em Minas Gerais.

A matéria citada indica que o

Acorda Brasil é uma estratégia publicitária que surgiu no final de 94, depois da vitória sobre Luiz Inácio Lula da Silva. Alguns integrantes daquele imenso cortejo de intelectuais e profes- 
sores do PSDB começaram a discutir a idéia de se fazer uma mobilização que reunisse o charme caridoso da campanha da fome do Betinho com a força dos barões da avenida paulista. (p. 18)

Depois da eleição, os publicitários foram chamados a continuar seu trabalho, nascendo, assim, o que Veja chamou de "marketing da academia".

Pelo jeito, a coisa vem seguindo até hoje. Inúmeras campanhas, sobretudo de televisão, nos habituaram, ao longo dos últimos anos, a vivenciar uma realidade educacional virtual, na qual aprendemos que vivemos no melhor dos mundos - da merenda escolar, dos livros didáticos, da avaliação, dos dinheiros oriundos do Fundão etc. Essa parece ser a estratégia adotada pelo atual governo - utilizar intensivamente a propaganda no sentido de convencer o cidadão de que se está fazendo uma excelente administração. A julgar por algumas notícias veiculadas, os recursos empregados para isso são também bastante consideráveis.

Segundo dados da Folha de S. Paulo, no ano passado, o governo federal gastou 39\% a mais do previsto em publicidade. $O$ montante à época recalculado iria chegar a $491 \mathrm{mi}$ Ihões de reais. Já no ano anterior, informa a mesma fonte, o dispêndio total da publicidade oficial foi de 354 milhões. Na jocosa expressão de Delfim Netto, "gastam por dia I I mil salários-mínimos em propaganda. Aí fica fácil." (Pinto, 1997). As notícias veiculadas em 1998 indicam que, dos dez maiores anunciantes do país, sete são órgãos do governo federal ou a ele ligados.

A idéia de difundir o que se faz não nasceu neste governo e está sendo debatida em razão dos diferentes sentidos que assume, e convém refletir a respeito. Alguns pontos merecem consideração especial:

a) Ao adotar o marketing como meio de melhorar a imagem da educação, passa-se a idéia de que os problemas estão sendo resolvidos pelo governo federal, quando os maiores encargos, por exemplo, no ensino fundamental, pertencem aos Estados e municípios que estão sendo sistematicamente esquecidos nesse processo. A propaganda da lei do Fundão falava em cifras de bilhões de reais, quando em verdade a contribuição financeira do governo federal é a menor de todas.

b) A utilização do marketing traz para o campo do emocional e do imaginário questões que exigem, no seu trato cotidiano, alto nível de racionalidade e de objetividade. Assim, os temas da avaliação escolar, dos provões, da avaliação dos livros didáticos etc, antes de chegarem à TV, deveriam passar por um certo consenso entre os que lidam com essas questões - os especialistas, os educadores e administradores etc. Não convém esquecer também que se avalia para algum objetivo, sobretudo para transformar, para melhorar a qualidade. E esta passagem, do dado avaliativo para a mudança, é um processo lento e persistente. Outro êxito contabilizado pelo marketing governamental refere-se ao programa Toda Criança na Escola, como 
tendo ultrapassado em 368 mil crianças a mais o número de alunos matriculados em fevereiro de 98. Mais realista, o presidente do Consed, Ramiro Wahrhtfig, diz que "sem a contagem populacional e o cruzamento com o censo nós não vamos ter como saber qual foi exatamente o progresso" (1998, p. 12).

c) $\bigcirc$ marketingem educação segue as regras tradicionais da propaganda política que, segundo a própria expressão do presidente $\mathrm{FHC}$ :

.....tem que contar sempre a mesma história, repetindo quem é bom e quem é ruim. Tem que ser os dois e vai mudando como na estrutura do mito, como Lévi Strauss. É binário: o bom e o mau. Etem que contar durante a campanha, de várias maneiras, o mesmo mito. No nosso caso, éa moeda....Você tem que chegar à estrutura mais elementar e insistir nisso. (Carvalho, 1995. p. I I 8)

Por acaso, essa visão teria algo a ver, por exemplo, com a forma de divulgação das avaliações dos livros didáticos, dos provões etc. passando a imagem de que nesses processos devem existir vilões e mocinhos, quando na realidade sobram quase sempre vítimas - que são os alunos que freqüentam o sistema educacional?

\section{OS NOVOS CENÁRIOS}

A modificação da estratégia global de condução da política educativa, com a substituição de uma atuação calcada no exercício do regime de colaboração (União, estados e municípios) e na maior participação de outros atores, como os professores, na definição das linhas básicas, como ocorreu nas propostas do Plano Decenal, vai criando resistências e dificuldades que podem inviabilizar esforços importantes para uma real transformação educacional do país.

A ação intensiva do MEC, ocupando espaços, sem uma interlocução que efetivamente exercite a colaboração com estados e municípios, responsáveis pela política de ensino fundamental, pode estar gerando novos fatos que são ainda difíceis de avaliar. $\bigcirc$ repasse de recursos diretamente às escolas, por exemplo, sem um envolvimento maior dos estados e municípios no acompanhamento das ações, pode significar, em muitos casos, desperdício ao invés de ganhos expressivos. A implantação da medida (Monteiro, 1995) provocou inúmeras observações de secretários estaduais que mencionaram desde a dificuldade de prestação de contas até o critério de cálculo de valor do repasse, tomando o número de alunos como base.

Já a secretária Silke Weber, de Pernambuco, identificou nessa medida um retrocesso do novo governo, indicando que a função de coordenação do MEC junto aos estados representava uma quebra nos avanços obtidos no governo anterior. De outra parte, o veto à exclusão do salário-educação como fonte de recursos para complementação dos fundos estaduais - contribuição importante do Consed - representou, na expressão de João Monlevade e Eduardo B. Ferreira, "um dos pecados capitais do Fundo de Manutenção e Desenvolvimento do Ensino Fundamental e de Valorização do Magistério - FUNDEF -" ( 1 997). As ações 
em curso na área educacional podem estar possibilitando, ainda, outras orientações que coloco para o debate.

\section{Recentralização educacional}

Em trabalho anterior (Garcia, 1997) mencionei que a função do MEC, abandonando a forma colaborativa mais tradicional junto a Estados e municípios, por uma postura tecnocrática agressiva, corria risco de provocar uma recentralização educacional, com prejuízos para todo o país. Aliás, esta temática não é nova entre nós. As análises de Guiomar Namo, J.E.Romão, Silke Weber e Márcia Aguiar, entre outros, ao longo dos últimos anos, vieram alertando sobre diferentes aspectos das relações entre centro e periferia do poder educativo, com suas peculiaridades e especificidades típicas de um país com diferentes níveis de desenvolvimento educacional.

O papel de equalização de oportunidades educacionais e orientação geral de política exigiria ações mais condizentes com processos de incorporação de parceiros na tarefa comum de reforçar os sistemas estaduais e municipais no enfrentamento de suas principais dificuldades. O texto constitucional de 1988, que é a referência básica a ser seguida, indica de maneira muito transparente a função do Ministério da Educação.

Muitos poderão alegar que o MEC consulta habitualmente tanto o CONSED quanto a UNDIME para tomar suas decisões, o que não deixa de ser verdade. Mas daí a afirmar que as soluções representam um consenso amadurecido dos atores envolvidos, vai uma grande distância - que pode ser medida na exata proporção da dependência que as unidades federadas têm do ministério. E nesse caso a variável política é fundamental. A prática cotidiana vem revelando que há estados fracos e estados fortes nessa relação de poder que se estabelece. Como a Constituição fixa a autonomia dos sistemas estaduais e municipais, especialmente no ensino básico, há orientações que podem ser seguidas ou não por determinadas unidades, embora, seguramente, outras sejam quase que compelidas a adotá-las, nem que seja apenas na sua aparência.

Uma das conseqüências provocadas pelas intervenções no estilo "pacotes" é a de que os estados e municípios, que já dispõem de quadros mais estáveis e competentes para desenvolver seus sistemas de ensino, estarão avançando muito além das proposições emanadas de um órgão central de poder. Em compensação, as regiões mais carentes, que tradicionalmente dependem do que é enviado por Brasília, são as menos preparadas para adotar inovações que efetivamente possam alterar a realidade na qual estão imersas. A lei do Fundo é indicativa de que não basta assinar uma lei e dizer que ela está em vigor. Estados mais organizados seguramente estão utilizando melhor os recursos do que aqueles que sequer dispõem de funcionários capazes de fazer cálculos simples de contabilidade como revela o texto de Monlevade e Ferreira, já mencionado. 
Novo papel da tecnocracia e dos educadores

Com a participação cada vez mais intensiva de instituições internacionais no financiamento da educação no país, há uma "agenda educativa" que tende a modificar a maneira de inserção da tecnocracia e dos educadores na definição das questões educacionais. Estas tendem a sofrer, cada vez mais, a mediação de instituições e normas que condicionam a forma de elaboração e apresentação de projetos, criando todo um ritual que vai progressivamente minando as estruturas decisórias. $\bigcirc$ conhecimento técnico de educação deve estar acoplado aos procedimentos previamente acordados entre o tomador (no caso, o governo) e o organismo financiador e tudo deve ser equacionado em razão desses entendimentos.

A forma de inserção em projetos ou programas, freqüentemente, leva as diferentes instâncias decisórias a desconhecerem o conjunto das atividades do ministério, agravando os problemas advindos da sucessão de ações que se esgotam em si e cujos efeitos não podem ser devidamente avaliados e acompanhados. Como muitas dessas ações já estão previamente definidas, o papel dos educadores, por exemplo, tende a ser de apoio - se mais ou menos competente é uma questão que só os especialistas poderão concluir - quando não de referendo ao que está proposto.

O atual governo já anunciou que a prioridade para o próximo mandato presidencial, em caso de reeleição, será o ensino de segundo grau, com ênfase nos cursos técnicos. Os recursos já estão sendo agilizados mediante empréstimo do Banco Interamericano de Desenvolvimento.

Tal maneira de conduzir os destinos da educação enseja indagações sobre o real envolvimento, sobretudo dos educadores, com as questões para as quais são chamados ao debate, especialmente no Conselho Nacional de Educação. A saída do Prof. Giannotti do Conselho Nacional de Educação revela que há, muitas vezes, um tipo de participação excludente, quando ela não se ajusta ao figurino pré-determinado pelo poder maior que comanda as decisões.

Em outras oportunidades, os educadores são chamados a fazer estudos em grupos e comissões, mas poucas vezes podem ver suas proposições debatidas amplamente. À medida em que as definições maiores já estão estabelecidas, tecnocratas e educadores, cada um em sua instância, devem cumprir seu papel, mesmo que isso desagrade a uns e a outros.

\section{Cidadania ou focalização?}

A crise das políticas sociais, com reflexo direto sobre os recursos investidos na manutenção e desenvolvimento das ações dos vários setores da administração, faz com que a busca de recursos internacionais vá se tornando uma rotina nos gabinetes ministeriais. Junto deles chegam também propostas de políticas, como já referi anteriormente. Uma dessas receitas, experimentada em outros países que aderiram antes de nós ao modelo proposto 
pelas grandes potências, diz que o Estado deve ser seletivo no atendimento de demandas, buscando atingir em primeiro lugar os que mais necessitam. Ou seja, o direito universal - de educação, saúde etc. deve ser estendido, prioritariamente, aos mais carentes. Aqui entra em ação o conceito de focalização, entendido como uma concentração de ação junto àqueles setores mais vulneráveis e de maior risco. Isto já ocorre com inúmeros programas - que passam a apresentar atuação mais restrita, porém mais direcionada para determinadas populações-alvo. Nesse caso, organizações comunitárias, não governamentais e empresas privadas passam a representar importante papel de reforço à ação do Estado, na medida em que este deixa certos lacunas em sua atuação.

O caso mais significativo para nós, até porque esta é uma proposta da "agenda internacional", freqüentemente citada na mídia, diz respeito ao financiamento da universidade pública. Muitos defendem que os alunos devem dar sua contribuição pagando anuidades. $\bigcirc$ assunto é polêmico e se insere no contexto mais geral dos parâmetros que devem orientar a ação do poder público em matéria educacional. O que está em jogo é o conceito de cidadania ampla, tal como definido na atual Constituição, diante de óticas de fundo economicista que procuram direcionar a ação do poder público para atendimento dos mais necessitados. Vale a pena acompanhar a discussão, até porque ela é permanentemente alimentada por debates e comentários, inclusive, muitos deles desrespeitosos para com a universidade brasileira.

No fundo dessa polêmica está o conceito de Estado e de sua forma de atuar em época de globalização como a que estamos vivendo. $\bigcirc$ Estado do Bem-Estar Social está morto, dizem os defensores do Estado mínimo. A cena política internacional está revelando que este último precisa existir para que o primeiro possa prosseguir para os que detêm o poder, permitindo, assim, que tal relação continue existindo.

\section{Os paradoxos da política}

A possibilidade de reeleição do atual presidente poderia, até, ensejar expectativa de que a descontinuidade fosse superada, assegurando condições para a continuidade da política educacional já traçada. Algumas questões, como por exemplo, a cultura da avaliação - do primário à universidade - indicam o caminho de um novo padrão de desempenho educativo, trazendo benefícios nos próximos dez anos para a melhoria do rendimento escolar. Só que isto já está sendo anunciado como um fato consumado, o que não deixa de ser um evidente exagero. $\bigcirc$ aumento dos níveis de escolaridade acontece por várias razões e não só por causa das avaliações.

Costumo citar o que me disse um dirigente do Ministério da Educação da Coréia, procurando explicar o alto rendimento dos estudantes coreanos. Segundo ele, os pais procuravam sempre passar aos filhos as lições de Confúcio como referenciais inspiradores de seu labor estudantil. Da mesma forma, o apoio à escola, como alguns projetos já fazem há alguns anos, é importante para ajudar cada uma delas a melhorar seu perfil, sua identidade, enfim, 
sentir-se participante de um processo social mais significativo.

No entanto, tais ações não representam a política em si. Elas são pré-condições ou mecanismos e, inclusive, quando bem executadas, provocam o afloramento de outras que são fundamentais da política educativa. A valorização social do professor, por exemplo, que não implica somente salários, é uma temática que está em debate em várias partes do mundo. A pouca atenção a ela, inclusive em países do Primeiro Mundo, faz com que já se busquem novos estímulos para tentar atrair pessoas que queiram trabalhar nessa área. Além do mais, essas orientações exigem também maiores investimentos e, além da continuidade, recomendam envolvimento de outros setores representativos da sociedade, até porque todos devem estar convencidos de pagar mais pela melhoria da educação.

As questões básicas, que configuram uma clara definição da educação como política pública relevante, num país continental e desigualmente desenvolvido, com distintas instâncias públicas respondendo pelos compromissos do Estado nessa área, estão vivendo sob o impacto dos projetos e das ações pontuais, como sempre veio sendo feito ao longo das últimas décadas. O regime de colaboração que retome idéias já acordadas e esquecidas, ao lado dos pactos da Infância e do de Valorização do Magistério, do qual o Fundão é apenas uma parte, são alguns consensos que se produziram ao longo dos últimos anos, envolvendo não apenas os responsáveis pela área educacional.

Muitos aguardam ainda que voltem os recursos congelados ou que foram drenados para outras áreas e que o diálogo interrompido retorne, sobretudo, com a decisão de fazer da educação uma prioridade absoluta de toda a sociedade.

Num eventual novo mandato do atual presidente, creio que o esquema de marketing agressivo, hoje já desgastado, deverá impor um novo patamar de desempenho, com retorno aos temas relevantes, recuperando energias para a educação do novo milênio.

\section{REFERÊNCIAS BIBLIOGRÁFICAS}

A ESCOLINHA do professor Fernando. Veja. 15 fev. 1995, p. 18.

AZEVEDO, J.M.L. de. A Educação como política pública. Campinas: Autores Associados, 1997. (Coleção Polêmicas do Nosso Tempo, v.56.)

BIRDSALL, N. FHC elogia Cristovam e a bolsa escola. Correio Brasiliense, 2 I jul. 1998. p.8.

BRAGA, R. O MEC e o poder. Educação Brasileira. Brasília, v.6, n. 13, 2 semestre, 1984.

BRASIL. Ministério da Educação e Cultura. Acordo Nacional: plano decenal de educação para todos - 1993-2003. Brasília, 1994.

CARVALHO, R.V.A. A Máquina fabulatória da mídia e o re-encantamento da política: a estrutura mítica das campanha eleitorais majoritárias. Caderno CRH, n.22, jan./jun. 1995. p. I 18. 
CUNHA, C. Plano Decenal: compromisso e alcance. In: O Plano Decenal. Brasília: MEC, 1994.

GARCIA, W. Tecnocratas e educadores. Porto Alegre, nov. 1997. [trabalho apresentado no XXVIII Simpósio da Anpae].

. Administração educacional em crise. São Paulo: Cortez; Campinas: Autores Associados, 1991 . (Coleção Polêmicas do Nosso Tempo, v.46)

GATTI, B.A., SAWAIA, S. Análise de programas e projetos desenvolvidos pelo MEC de 1975 a 1986. São Paulo: FCC, 1987.

GOLDEMBERG, J. A Educação nacional. O Estado de S. Paulo, I3 jul. 1992.

HINGEL, M. Discurso de posse como ministro da Educação e do Desporto, 6 out. 1992.

LÜCE, M.B., FÁVERO, O., HADDAD, S. Sobre a contribuição das comissões estaduais do PNAC: subsídios para uma avaliação. 1992. (versão preliminar)

MELLO, F.C. de. Formação básica, ciência e tecnologia. Folha de S. Paulo, 6 fev. 1992. p.3 [coluna Tendências e Debates]

MONLEVADE, I., FERREIRA, E.B. O Fundef e seus pecados capitais. Brasília: Idea, 1997.

MONTEIRO, M. Repasse direto às escolas enfrenta críticas. Correio Braziliense. 12 fev. 1995.

OLIVEIRA, R.P. Educação e cidadania: o direito à educação na Constituição de 1998 da República Federativa no Brasil. São Paulo, 1998. Tese (dout.) FEUSP.

PINTO, L.C. FHC gasta 39\% a mais em publicidade. Folha de S. Paulo, 22 out. 1997.

SAVIANI, D. Da nova $\angle D B$ ao novo Plano Nacional de Educação: por uma outra política educacional. Campinas: Autores Associados, 1998.

SILVA, C.E.L. Banco Mundial discute a educação brasileira. Folha de S. Paulo, 30 mar. 199I . p.4-4.

VIEIRA, S. L. Planejamento e política educacional: o fio e a trama. 1998. mimeo. . Política educacional em tempos de transição( 1985- 1995). Fortaleza, 1998. mimeo.

WAHRTFIG, R. As Metas do governo FHC: Educação. Correio Brasiliense, 26 jul. I998. p. I 2. 
